\title{
Coprorhexy, coprophagy, and coprochaly in the copepods Calanus helgolandicus, Pseudocalanus elongatus, and Oithona similis
}

\author{
Morten H. Iversen ${ }^{1,2, *}$, Louise K. Poulsen ${ }^{1}$ \\ ${ }^{1}$ Danish Institute for Fisheries Research, Department of Marine Ecology and Aquaculture, Kavalergården 6, \\ 2920 Charlottenlund, Denmark \\ ${ }^{2}$ Alfred Wegener Institute for Polar and Marine Research, Am Handelshafen 12, 27570 Bremerhaven, Germany
}

\begin{abstract}
Studies of fecal pellet flux show that a large percentage of pellets produced in the upper ocean is degraded within the surface waters. It is therefore important to investigate these degradation mechanisms to understand the role of fecal pellets in the oceanic carbon cycle. Degradation of pellets is mainly thought to be caused by coprophagy (ingestion of fecal pellets) by copepods, and especially by the ubiquitous copepods Oithona spp. We examined fecal pellet ingestion rate and feeding behavior of $O$. similis and 2 other dominant copepod species from the North Sea (Calanus helgolandicus and Pseudocalanus elongatus). All investigations were done with fecal pellets as the sole food source and with fecal pellets offered together with an alternative suitable food source. The ingestion of fecal pellets by all 3 copepod species was highest when offered together with an alternative food source. No feeding behavior was determined for $O$. similis due to the lack of pellet capture in those experiments. Fecal pellets offered together with an alternative food source increased the filtration activity by $C$. helgolandicus and $P$. elongatus and thereby the number of pellets caught in their feeding current. However, most pellets were rejected immediately after capture and were often fragmented during rejection. Actual ingestion of captured pellets was rare $(<37 \%$ for $C$. helgolandicus and $<24 \%$ for $P$. elongatus), and only small pellet fragments were ingested unintentionally along with alternative food. We therefore suggest coprorhexy (fragmentation of pellets) to be the main effect of copepods on the vertical flux of fecal pellets. Coprorhexy turns the pellets into smaller, slower-sinking particles that can then be degraded by other organisms such as bacteria and protozooplankton.
\end{abstract}

KEY WORDS: Fecal pellet · Grazing · Functional response · Visual observation · Video recording

\section{INTRODUCTION}

Fecal pellets in the sea are degraded by bacteria (Cho \& Azam 1988) and possibly by zooplankton such as copepods (Paffenhöfer \& Strickland 1970). Copepods degrade pellets through coprophagy (ingestion of pellets), coprorhexy (fragmentation of pellets), and coprochaly (loosening of pellets) (Paffenhöfer \& Strickland 1970, Lampitt et al. 1990, Noji et al. 1991). Coprophagy is the best documented of the degradation processes. Paffenhöfer \& Strickland (1970) observed
Calanus helgolandicus ingesting fecal pellets even in the presence of algal food. This ability was also shown for C. helgolandicus nauplii (Green et al. 1992). Further, grazing rates of fecal pellets have been obtained for many other species of copepods; for example, Acartia omorii ingests fecal pellets at high rates (Viitasalo et al. 1999), and Eucalanus pileatus consumes nauplii fecal pellets at the same rate as algae of similar size (Paffenhöfer \& Knowles 1979). Coprorhexy was suggested by Lampitt et al. (1990), who observed copepods to be highly adept at breaking up their own fecal 
pellets while only ingesting small fragments. Noji et al. (1991) observed coprochaly in Acartia clausi, C. helgolandicus, and Pseudocalanus elongatus.

Although these studies have indicated the existence of fecal pellet grazing behavior by copepods, only 2 studies have visually observed feeding behavior, in Acartia tonsa (Poulsen \& Kiørboe 2005) and Eucalanus pileatus (Paffenhöfer \& Van Sant 1985). Visual observations of the feeding behavior of $A$. tonsa grazing on fecal pellets suggested that $A$. tonsa mainly degrades fecal pellets via coprorhexy (95\%; Poulsen \& Kiørboe 2005). Paffenhöfer \& Van Sant (1985) observed E. pileatus ingesting fewer fecal pellets than live and dead phytoplankton cells, indicating a preference for food particles other than pellets. Furthermore, pellets arriving at the mouth were opened or slightly macerated before ingestion when rejection did not occur (Paffenhöfer \& Van Sant 1985), indicating coprorhexious feeding behavior for E. pileatus.

We investigated the feeding behavior of Calanus helgolandicus, Oithona similis, and Pseudocalanus elongatus on copepod fecal pellets produced by Acartia tonsa feeding on Rhodomonas salina. This was done through simultaneous incubation experiments and video recordings of feeding behavior in the presence and absence of alternative food. The species investigated in this study were chosen due to their differences in size and feeding behavior, and due to their common presence in temperate areas. C. helgolandicus and $P$. elongatus are suspension feeders that detect their food via chemosensory perception using a feeding current while cruising slowly through the water (Andrews 1983). O. similis is an ambush feeder that 'hangs' in the water and only launches an attack when a prey particle is detected via hydromechanical disturbances generated by the prey (Kiørboe \& Visser 1999, Svensen \& Kiørboe 2000).

\section{MATERIALS AND METHODS}

Phytoplankton. Thalassiosira weissflogii (a diatom), Rhodomonas salina (a cryptophyte), and Heterocapsa triquetra (a dinoflagellate) were maintained in exponential growth in f/2 medium (Guillard 1975). The cultures were kept at a constant light:dark cycle (12:12 h) in filtered $(0.2 \mu \mathrm{m})$ seawater $(\sim 33 \%)$ at $18^{\circ} \mathrm{C}$ and used as food for zooplankton cultures. Only $R$. salina $(9 \times$ $12 \mu \mathrm{m}$ in size) was used as a food item during the production of fecal pellets.

Zooplankton. Calanus helgolandicus females were collected in October 2004 and August 2005 in the north-eastern North Sea and kept in culture in filtered $(0.2 \mu \mathrm{m})$ seawater $(\sim 33 \%)$ at $14^{\circ} \mathrm{C}$, reared on a mixed diet of Rhodomonas salina, Thalassiosira weissflogii, and Heterocapsa triquetra. Oithona similis was collected in November 2004 in The Sound (Øresund, Denmark) and kept in natural seawater from The Sound $(\sim 22 \%)$ at $12^{\circ} \mathrm{C}$. Pseudocalanus elongatus was collected in August 2003 in the North Sea, kept in culture in filtered seawater $(\sim 33 \%)$ at $14^{\circ} \mathrm{C}$, and reared on a mixed diet of $R$. salina, T. weissflogii, and $H$. triquetra. Acartia tonsa was kept in a laboratory culture in filtered $(0.2 \mu \mathrm{m})$ seawater $(\sim 33 \%)$ at The Danish Institute for Fisheries Research at $18^{\circ} \mathrm{C}$ and reared on $R$. salina (Støttrup et al. 1986). All copepods were acclimated to the experimental conditions for $>24 \mathrm{~h}$ prior to each experiment (Table 1). Fecal pellets offered as food for the copepods in both grazing and behavior experiments were produced by adult $A$. tonsa grazing on $R$. salina at excess concentration (>713 $\mu \mathrm{g} \mathrm{C} \mathrm{l}^{-1}$; Kiørboe et al. 1985) for $<18 \mathrm{~h}$. This simulated pellets produced under bloom conditions or when the copepod locates a food patch such as a subsurface bloom. Such pellets may be attractive food particles due to high pellet production rates, low gut passage times, and relatively low assimilation efficiencies (Besiktepe \& Dam 2002) resulting in fecal pellets of high nutritional value. Thus, fecal pellets were between 0.5 and $18 \mathrm{~h}$ old at the start of the incubation. The average fecal pellet length and width for pellets offered in the experiments was (mean \pm SD) $96 \pm 26$ and $28 \pm 5 \mu \mathrm{m}$, respectively.

Grazing experiments. Fecal pellet clearance rates and ingestion rates of adult females were determined in both the presence and absence of alternative food (Table 1). Incubations were run for $24 \mathrm{~h}$, in a 12:12 h light:dark cycle, and on a plankton wheel rotating at $\sim 1 \mathrm{rpm}$. This rotation speed was chosen to keep the pellets suspended and to have minimum effect on the copepods. Ploug et al. (in press) found sinking velocities of $28 \pm 3 \mathrm{~m} \mathrm{~d}^{-1}$ for similar sized pellets produced by Temora longicornis feeding on Rhodomonas salina. At a rotation speed of $1 \mathrm{rpm}$, the experimental bottles (8 $\mathrm{cm}$ diameter) were in each position (upright, sideways, and upside down) for $\sim 15 \mathrm{~s}$. The pellets sank $0.5 \pm 0.005 \mathrm{~cm}$ during $15 \mathrm{~s}$; therefore, only pellets near the side of the vessel at the beginning of the experiment had their motion affected during incubation. When an alternative food source was present, it was always at a concentration of $3 \times 10^{6}$ cells $1^{-1}$ to ensure the presence of alternative food during the whole incubation. A wide range of pellet concentrations was used to determine the functional response in pellet clearance to pellet concentration (Table 1). Only pellet concentrations $<2$ pellets $\mathrm{ml}^{-1}$ represent pellet concentrations found in situ. The pellets offered as food were distinguished from the pellets produced during the experiments due to a visually recognizable size difference. However, when offering Pseudocalanus elongatus fecal pellets together with an alternative food 
Table 1. Experimental design. Copepod species (Calanus helgolandicus, Oithona similis, and Pseudocalanus elongatus), alternative food source (Thalassiosira weissflogii, natural plankton $<20 \mu \mathrm{m}$, and Rhodomonas salina), female concentration, equivalent spherical diameter (ESD), and concentrations of fecal pellets offered during the incubations. rep.: number of replicates at each pellet concentration; con.: number of replicates of control bottles run in parallel with the experimental bottles at 3 different concentrations (low, intermediate, and high); P: fecal pellets as sole food source; $\mathrm{P}+$ alga: fecal pellets in the presence of an alternative food source; -: not investigated

\begin{tabular}{|c|c|c|c|c|c|c|c|c|}
\hline \multirow[t]{2}{*}{ Copepod species } & \multirow[t]{2}{*}{$\begin{array}{l}\text { Alternative } \\
\text { food source }\end{array}$} & \multirow[t]{2}{*}{$\begin{array}{l}\text { Female conc. } \\
\quad\left(\text { ind. }^{-1}\right)\end{array}$} & \multirow[t]{2}{*}{$\begin{array}{l}\text { Temp. } \\
\left({ }^{\circ} \mathrm{C}\right)\end{array}$} & \multirow[t]{2}{*}{$\begin{array}{l}\text { Salinity } \\
(\% \circ)\end{array}$} & \multirow[t]{2}{*}{$\begin{array}{c}\text { Bottle } \\
\text { volume (ml) }\end{array}$} & \multirow[t]{2}{*}{$\begin{array}{l}\mathrm{ESD} \\
(\mu \mathrm{m})\end{array}$} & \multicolumn{2}{|c|}{$\begin{array}{l}\text { Fecal pellet conc. } \\
\quad\left(\text { pellets } \mathrm{ml}^{-1}\right)\end{array}$} \\
\hline & & & & & & & $\mathrm{P}$ & $P+$ alga \\
\hline \multicolumn{9}{|c|}{ Grazing experiment } \\
\hline C. helgolandicus & T. weissflogii & $\begin{array}{c}1.6 \\
\text { (5 rep., } 5 \text { con.) }\end{array}$ & 14 & 32 & 615 & 50 & \multicolumn{2}{|c|}{$0.2-4.8^{\mathrm{a}}$} \\
\hline O. similis & $\begin{array}{c}\text { Natural plankton }<20 \mu \mathrm{m} \\
R . \text { salina }\end{array}$ & $\begin{array}{c}25 \\
\text { (3 rep., } 3 \text { con.) }\end{array}$ & 12 & 22 & 320 & 47 & \multicolumn{2}{|c|}{$0.3-8^{\mathrm{a}}$} \\
\hline P. elongatus & - & $\begin{array}{c}13 \\
\text { (3 rep., } 3 \text { con.) }\end{array}$ & 15 & 36 & 615 & 52 & $0.2-4.8$ & - \\
\hline \multicolumn{9}{|c|}{ Behavior experiment } \\
\hline C. helgolandicus & T. weissflogii & 7.8 & 14 & 33 & 637 & 45 & $0-11$ & $0.3-9$ \\
\hline O. similis & R. salina & 29.4 & 14 & 21 & 408 & 50 & $0.1-10$ & $0-9$ \\
\hline P. elongatus & T. weissflogii & 19.6 & 12 & 33 & 408 & 50 & $0-23$ & $0.1-15$ \\
\hline
\end{tabular}

source, it was not possible to distinguish between 'food pellets' and pellets produced by $P$. elongatus itself, and thus fecal pellet clearance and ingestion rates could not be estimated. It was possible to distinguish between pellets produced by $P$. elongatus and food pellets in the absence of an alternative food source due to color and differences in structure. Ingestion and clearance rates were calculated using the equations of Frost (1972).

Behavior experiments. Grazing behavior was investigated by filming adult females feeding on a range of fecal pellet concentrations in the presence and absence of alternative food (Table 1). Filming was conducted in a cylindrical aquarium (Calanus helgolandicus: $10 \mathrm{~cm}$ diameter, $7.9 \mathrm{~cm}$ depth; Oithona similis and Pseudocalanus elongatus: $7.9 \mathrm{~cm}$ diameter, $7.9 \mathrm{~cm}$ depth). The aquarium was placed on a rolling table that was rotated at $\sim 1 \mathrm{rpm}$ to keep fecal pellets suspended. The rotation of the aquarium opposed the sinking velocity of the pellets, and they were not near the side of the rotating aquarium. The filming equipment consisted of a CCD video camera (Mintron MTV$1802 \mathrm{CB}$ ) equipped with a $105 \mathrm{~mm}$ lens (Nikon Micro Nikkor 1:2.8) and connected to a video cassette recorder, a time-code generator, and a monitor. Infrared illumination was provided from behind by a light-emitting diode (LED), which was collimated through a condenser. Females were acclimated to the fecal pellet concentration in the aquarium for $1 \mathrm{~h}$ prior to filming. Alternative food was added to the aquarium after 40 min of filming, and the females were again acclimated for $1 \mathrm{~h}$ prior to filming (Table 1). Fecal pellet concentrations were measured before and after each period of filming (40 min). The average fecal pellet concentration during filming was used as the experimental concentration. One female at a time was kept in focus and followed for at least $1 \mathrm{~min}$ if possible. The video tapes were analyzed frame by frame, and the fraction of time a female spent filtering, sinking, or jumping was recorded for approximately $1 \mathrm{~min}$ per female. The behavior of 4 females was analyzed at each fecal pellet concentration, in the absence and presence of alternative food. Periods when females were close to the aquarium wall were excluded from the analysis. The numbers of rejected and ingested fecal pellets observed during a total of $30 \mathrm{~min}$ of filming with a female in focus were recorded for each pellet concentration in the presence and absence of alternative food (half-hour analysis, see Tables $2 \& 3$ ).

Counting procedure. After incubation, the fecal pellets were collected on a $15 \mu \mathrm{m}$ screen, preserved in acid Lugol's solution, and counted under an inverted microscope. The filtrate from the $15 \mu \mathrm{m}$ screen did not contain pellets or recognizable fragments. Pellet fragments (end parts only) were counted as a half-pellet. The average volume and equivalent spherical diameter (ESD) of the pellets were calculated from measurements of length and width of at least 30 intact fecal pellets in each experiment.

Statistical analysis. Student's $t$-test (SigmaStat version 3.1) was used to test for differences between treatments in fecal pellet clearance rates. The ingestion 
rate, suspension feeding activity (\%), feeding bout duration, number of jumps, jump duration, and sink duration were tested for differences between treatments with an analysis of covariance (ANCOVA; SPSS version 13.0), using the interactions between the treatments (absence/presence of alternative food) and average fecal pellet concentration (covariate). Suspension feeding activity (\%) was the percentage of time a copepod spent filtrating the water: (time spent filtrating/sum of all activity) $\times 100$.

\section{RESULTS}

\section{Clearance and ingestion}

\section{Calanus helgolandicus}

The clearance of fecal pellets was variable with no clear trend and was independent of pellet concentration both with and without the alternative food (Thalassiosira weissflogii; Fig. 1A). Maximum pellet clearance (mean $\pm \mathrm{SD}$ ) was $172 \pm 125 \mathrm{ml}$ female $\mathrm{e}^{-1} \mathrm{~d}^{-1}$ in the presence of $T$. weissflogii and $205 \pm 198 \mathrm{ml} \mathrm{female}^{-1} \mathrm{~d}^{-1}$ when pellets were offered alone (Fig. 1A). The inges-
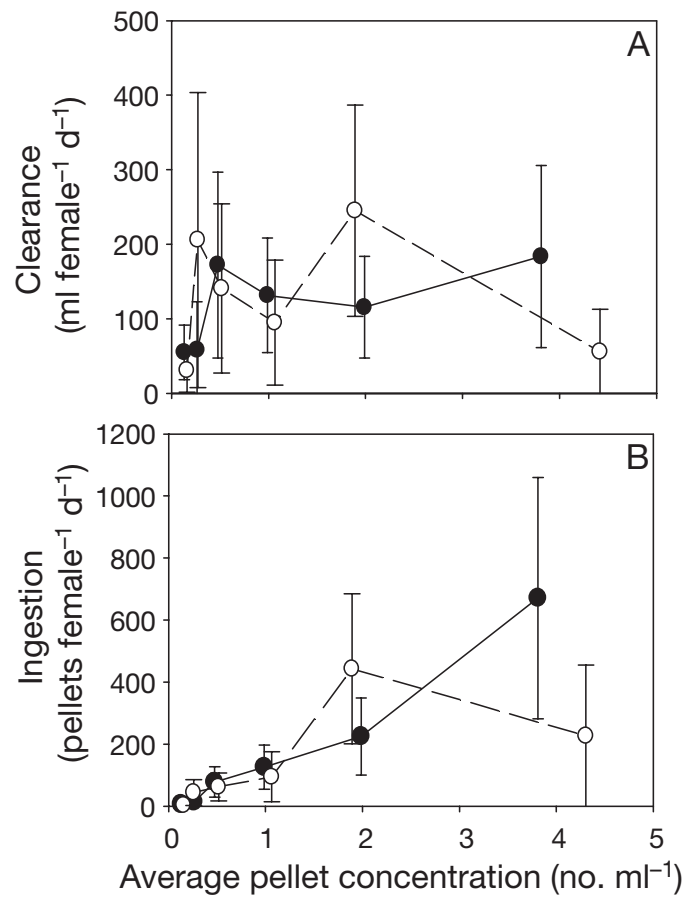

Fig. 1. Calanus helgolandicus. Average (A) clearance and (B) ingestion rates of fecal pellets with $(\bullet)$ or without $(\mathrm{O})$ Thalassiosira weissflogii as an alternative food source. Fecal pellets were produced by Acartia tonsa adults feeding on Rhodomonas salina. Fecal pellet clearance and ingestion rates were estimated according to Frost (1972). Error bars indicate \pm SD tion rate increased with increasing pellet concentration in the presence of alternative food to a level of $671 \pm 389$ pellets female ${ }^{-1} \mathrm{~d}^{-1}$ (Fig. 1B), equivalent to $43 \pm 32 \times 10^{6} \mu^{3}$ pellet material female ${ }^{-1} \mathrm{~d}^{-1}$. When offered only pellets, however, the pellet ingestion reached a maximum $\left(443 \pm 242\right.$ pellets female $\left.\mathrm{e}^{-1} \mathrm{~d}^{-1}\right)$ at food concentrations of $\sim 2$ pellets $\mathrm{ml}^{-1}$, whereupon it decreased again (Fig. 1B); the maximum ingestion was $23 \pm 16 \times 10^{6} \mu^{3}$ female ${ }^{-1} \mathrm{~d}^{-1}$. Clearance and ingestion of fecal pellets by $C$. helgolandicus were statistically independent of the presence or absence of $T$. weissflogii (clearance maximum: $\mathrm{p}=0.757$, Student's $t$-test; ingestion rate $\mathrm{p}=0.287$, $\mathrm{ANCOVA}_{i}$ Fig. 1 ).

\section{Pseudocalanus elongatus}

Clearance rate with pellets as the sole food for Pseudocalanus elongatus was constant at pellet concentrations from 0 to 1.5 pellets $\mathrm{ml}^{-1}$, whereupon it decreased. Maximum clearance was $72 \pm 14 \mathrm{ml}$ female ${ }^{-1} \mathrm{~d}^{-1}$ (Fig. 2A).

The ingestion rate of fecal pellets increased asymptotically with pellet concentration toward a maximum ingestion rate of $121 \pm 55$ pellets female $\mathrm{e}^{-1} \mathrm{~d}^{-1}$ at pellet concentrations $>1.5$ pellets $\mathrm{ml}^{-1}$, resulting in a volume ingestion of $9 \pm 5 \times 10^{6} \mathrm{\mu m}^{3}$ female $^{-1} \mathrm{~d}^{-1}$ (Fig. 2B).

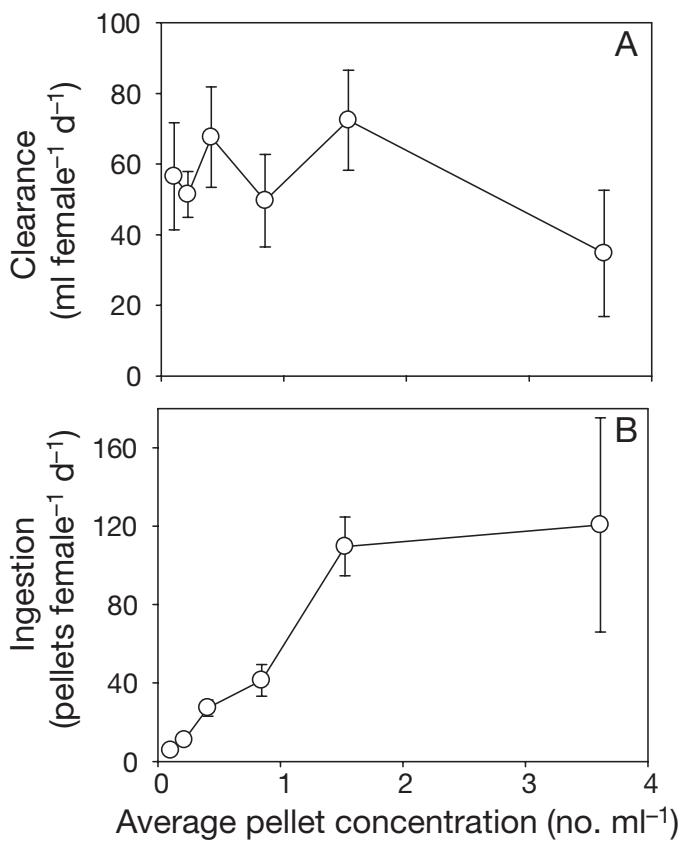

Fig. 2. Pseudocalanus elongatus. (A) Clearance and (B) ingestion rates of fecal pellets offered as sole food source. Fecal pellets were produced by Acartia tonsa adults feeding on Rhodomonas salina. Fecal pellet clearance and ingestion rates were estimated according to Frost (1972). Error bars indicate $\pm \mathrm{SD}$ 


\section{Oithona similis}

The clearance rate of fecal pellets was dependent on pellet concentration in both the presence and absence of an alternative food source (Fig. 3A). The presence of a monoculture of Rhodomonas salina induced significantly higher maximum clearance rates than when the pellets were offered as the sole food $(p=0.007$, Student's $t$-test). No significant difference was found between maximum clearance of pellets offered as the sole food and fecal pellets offered with a natural plankton assemblage $(<20 \mu \mathrm{m})$, or between the 2 treatments with alternative food $(\mathrm{p}>0.1$, Student's $t$-test; Fig. 3A,B). Maximum clearance rates $(24 \pm 1,29 \pm 17$, and $9 \pm 5 \mathrm{ml}$ female $\mathrm{f}^{-1} \mathrm{~d}^{-1}$ for pellets offered with $R$. salina, natural plankton $<20 \mu \mathrm{m}$, and as the sole food, respectively) were reached at fecal pellet concentrations of $\sim 0.5$ pellets $\mathrm{ml}^{-1}$ in both the presence and absence of alternative food.

The ingestion rates of fecal pellets by Oithona similis increased with increasing pellet concentration in the presence of alternative food (Fig. 3C,D). The maximum ingestion in the presence of an alternative food source was $0.9 \pm 1.2 \times 10^{6} \mu^{3}$ female $^{-1} \mathrm{~d}^{-1}$ for the monoculture and $1.1 \pm 1.3 \times 10^{6} \mu^{3}$ female ${ }^{-1} \mathrm{~d}^{-1}$ for the natural phytoplankton $<20 \mu \mathrm{m}$ at concentrations of 7 and 2.8 pellets $\mathrm{ml}^{-1}$, respectively (Fig. 3C,D). When pellets were offered as the sole food, high variation in ingestion rates was observed. The maximum pellet ingestion was found at 6 pellets $\mathrm{ml}^{-1}$, at which $0.6 \pm 1 \times 10^{6}$ $\mu \mathrm{m}^{3}$ female $\mathrm{e}^{-1} \mathrm{~d}^{-1}$ was ingested (Fig. 3C). No significant difference in the ingestion rates was found between the different treatments ( $\mathrm{p}>0.1$, ANCOVA), although higher ingestions were observed at concentrations $<4$ pellets $\mathrm{ml}^{-1}$ when an alternative food source was present (Fig. 3C,D).

Thus, the copepods cleared fecal pellets in both the absence and presence of alternative food. Further, the presence of an alternative food source seemed to increase the clearance rates and ingestion rates of fecal pellets.

\section{Feeding behavior}

For all experiments, the suspended fecal pellets sank slowly, but as the aquarium turned, the pellets were kept suspended as did the animals when not moving.

Oithona similis is an ambush feeder and perceives only moving particles. It attacks a particle by jumping toward it and making a short burst of filtration upon encounter. Ambush feeding and ingestion of Rhodomonas salina cells were observed during filming, but no pellets were ingested. Since $O$. similis is an ambush feeder, its feeding activity was recorded as jump activity (jumps $\min ^{-1}$; Fig. 4A). No observations of encounters of fecal pellets were recorded. Further, the presence or absence of $R$. salina did not influence the feeding behavior of $O$. similis, as no significant difference was observed in the number of jumps, jump duration, and sink duration ( $\mathrm{p}>0.05$, ANCOVA; Fig. 4). Clearly, O. similis viewed $R$. salina to be more attractive food particles than fecal pellets, which elicited no feeding response during the $\sim 7 \mathrm{~h}$ of filming.

The feeding behavior of Calanus helgolandicus consisted of short continuous feeding bouts interrupted by brief periods of sinking. During the feeding bouts, a feeding current was generated, which pulled the copepod forward while it collected the particles caught in the current ('suspension feeding'). Pellet encounters occurred only during suspension feeding and often seemed unintentional with effort made to reject the pellets (Table 2, Fig. 5). The rejection was made with a
Fig. 3. Oithona similis. $(\mathrm{A}, \mathrm{B})$ Clearance rate and $(\mathrm{C}, \mathrm{D})$ ingestion rate of fecal pellets by $O$. similis are measured with fecal pellets as the sole food $(\mathrm{O})$, offered together with Rhodomonas salina $(\bullet)$, and as pellets offered with a natural plankton community $(<20 \mu \mathrm{m})$ from The Sound (Øresund, Denmark; O). Fecal pellets were produced by Acartia tonsa adults feeding on Rhodomonas salina. Fecal pellet clearance and ingestion rates were estimated according to Frost (1972). Error bars indicate $\pm \mathrm{SD}$ 

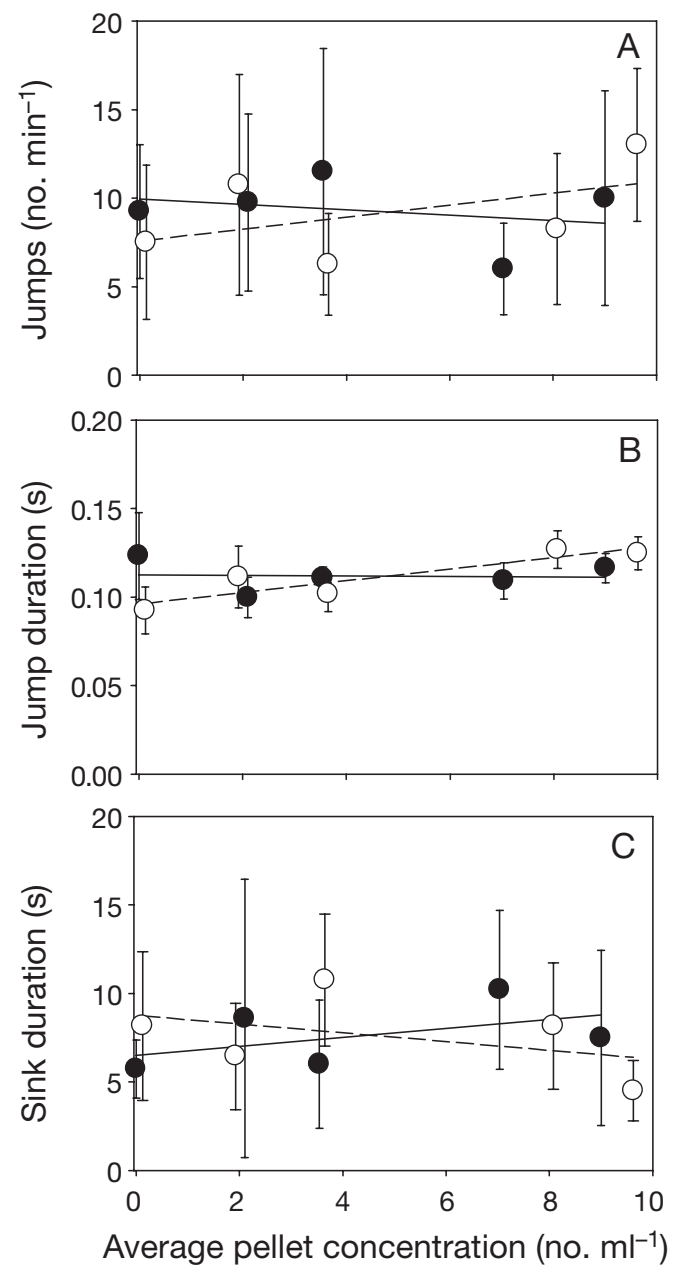

Fig. 4. Oithona similis. Female feeding behavior as a function of fecal pellet concentration in the absence $(O$, dashed lines) and presence $(\bullet$, solid lines) of an alternative food source (Rhodomonas salina). Average (A) number of jumps per minute, (B) jump duration in seconds, and (C) sink duration. Each point is the mean \pm SD of the behavior of 3 females analyzed for approximately 1 min each powerful water thrust created by kicking the swimming legs. Coprorhexious behavior was observed from the rupture of some pellets during rejection. C. helgolandicus was also observed to feed coprochalously but only on large fecal pellets. In case of coprochaly, the pellet was handled by the feeding appendages for several seconds (5 to $\leq 20 \mathrm{~s}$ ), whereupon it was rejected. After rejection, the shape of the pellet was clearly more fuzzy and ruptured due to apparent removal of parts of the periotrophic membrane. Only small or fragmented pellets were ingested, mainly along with the alternative food. Selective capture of fecal pellets was observed on a few occasions. This was seen as purposeful circling around a pellet while continuously filtering in short bursts until the pellet was captured. However, this effort rarely resulted in actual pellet ingestion. More often the pellet was rejected immediately after capture.

The presence of Thalassiosira weissflogii as an alternative food source induced a significant increase in suspension feeding activity of Calanus helgolandicus ( $>35 \% ; \mathrm{p}=0.0001$, ANCOVA) whereas the average suspension feeding activity was low $(<21 \%)$ when it grazed fecal pellets as the sole food source (Fig. 5A). No significant difference was found between the duration of feeding bouts with or without $T$. weissflogii as an alternative food source ( $p>0.1$, ANCOVA; Fig. 5B). The sink duration was significantly higher when pellets were offered as the sole food ( $p=0.006$, ANCOVA; Fig. 5C). The increase in suspension feeding activity when T. weissflogii was present led to increased encounters of fecal pellets. The percentage of rejections of total encounters remained constant between 75 and $90 \%$, independent of the total number of encounters, and the presence or absence of an alternative food source.

Pseudocalanus elongatus is a suspension feeder, and encounters of fecal pellets were only observed

Table 2. Calanus helgolandicus. Fecal pellet feeding behavior in the presence (+alga) or absence (-alga) of alternative food (Tha-

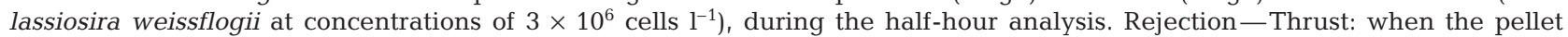
caught in the feeding current was forcibly thrust away from the copepod; Filtration: when the pellet caught in the filtration current smoothly moved through the feeding appendages and out again. Avoidance: when the presence of the pellet induced an escape jump in the female. Ingestion: when the pellet was actually ingested. Encounter: number of observed encounters of fecal pellets (rejection, avoidance, or ingestion) during the half-hour analysis. -: not investigated

\begin{tabular}{|c|c|c|c|c|c|c|c|c|c|c|}
\hline \multirow{3}{*}{ 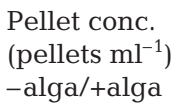 } & \multicolumn{4}{|c|}{ Rejection } & \multicolumn{2}{|c|}{ Avoidance } & \multicolumn{2}{|c|}{ Ingestion } & \multicolumn{2}{|c|}{ Encounter } \\
\hline & & rust & Filtr & ation & & & & & & \\
\hline & -alga & + alga & -alga & +alga & -alga & + alga & -alga & + alga & -alga & + alga \\
\hline $0.25 / 0$ & 0 & 0 & 0 & 0 & 0 & 0 & 0 & 0 & 0 & 0 \\
\hline $2.25 / 2.38$ & 2 & 4 & 9 & 9 & 1 & 2 & 9 & 10 & 24 & 40 \\
\hline$-/ 4$ & - & 1 & - & - & - & 5 & - & 2 & - & 22 \\
\hline $5.63 / 5.38$ & 1 & 2 & 0 & 0 & 1 & 3 & 0 & 12 & 13 & 97 \\
\hline $8.75 / 8.75$ & 0 & 2 & 17 & 17 & 0 & 18 & 17 & 9 & 86 & 79 \\
\hline $11.25 /-$ & 2 & - & 5 & 5 & 4 & - & 5 & - & 38 & - \\
\hline
\end{tabular}



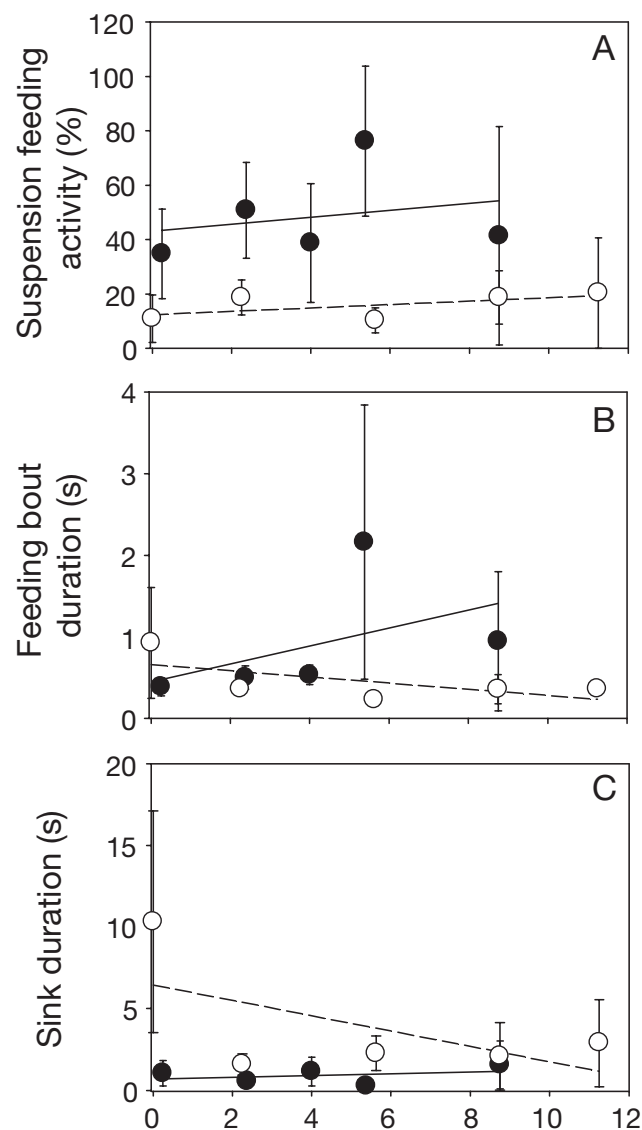

Average pellet concentration (no. $\mathrm{ml}^{-1}$ )

Fig. 5. Calanus helgolandicus. Female feeding behavior as a function of fecal pellet concentration in the absence $(O$, dashed lines) and presence (•, solid lines) of an alternative food source (Thalassiosira weissflogii). Average (A) suspension feeding activity as a percentage of total activity, (B) feeding bout duration in seconds, and (C) sink duration in seconds. Each point is the mean \pm SD of the behavior of 3 females analyzed for approximately 1 min each

during filtration bouts. Often the encounters with fecal pellets seemed unintentional, with efforts made to reject the pellets. The rejection often involved large bursts of water creating a strong current that pushed the pellet away. At other times, the rejection was accomplished by swimming in circles while kicking with both feeding and swimming appendages in an attempt to reject the pellet, as if it caused handling problems. Rejection caused physical stress, which at times was observed to rupture and fragment the fecal pellets (coprorhexy). Only small pellets or pellet fragments were ingested, mainly along with alternative food.

The presence of Thalassiosira weissflogii induced a significantly higher suspension feeding activity by Pseudocalanus elongatus $(p=0.002$, ANCOVA; Fig. 6A), although this difference was most pro- nounced at low pellet concentrations of $<2$ pellets $\mathrm{ml}^{-1}$. No significant difference was observed in feeding bout duration in the presence of alternative food $(p=0.9$, ANCOVA; Fig. 6B). Sink duration increased significantly when pellets were offered as the sole

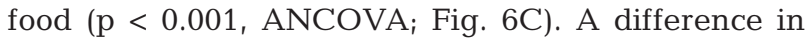
the number of pellet encounters was observed depending on the presence or absence of phytoplankton (Table 3).

Fecal pellet encounter and ingestion rates

The total number of encounters between fecal pellets and calanoid copepods (Calanus helgolandicus and Pseudocalanus elongatus) was estimated from the video observations (Tables $2 \& 3$ ). Fecal pellets were
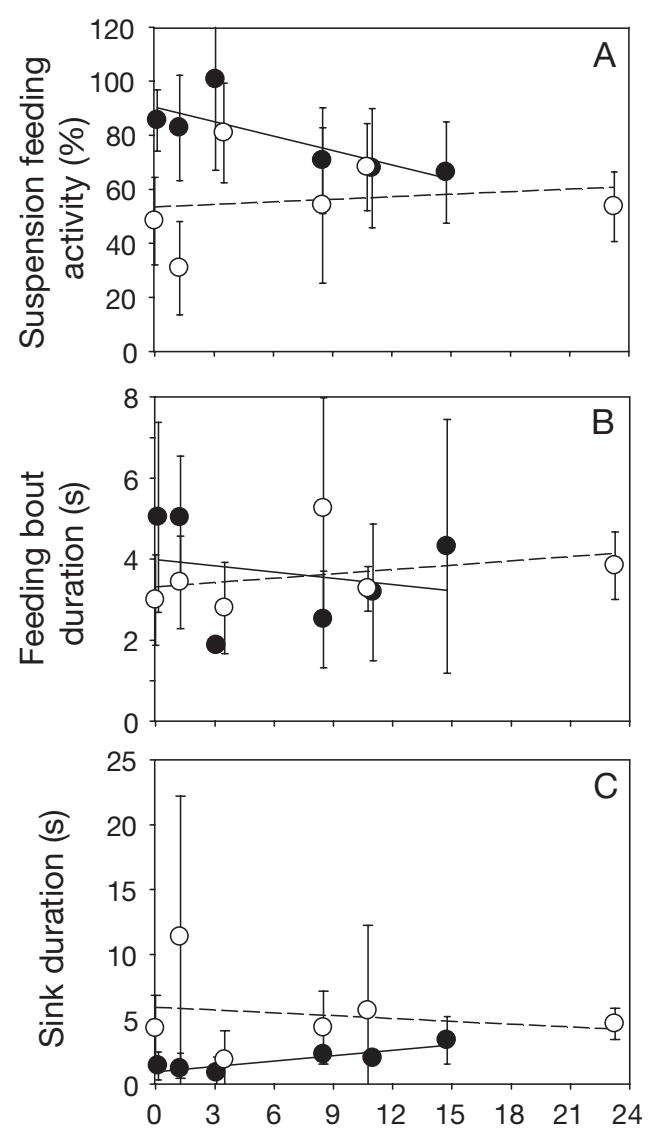

Average pellet concentration (no. $\mathrm{ml}^{-1}$ )

Fig. 6. Pseudocalanus elongatus. Female feeding behavior as a function of fecal pellet concentration in the absence $(O$, dashed lines) and presence (•, solid lines) of an alternative food source (Thalassiosira weissflogii). Average (A) suspension feeding activity as a percentage of total activity, (B) feeding bout duration in seconds, and (C) sink duration in seconds. Each point is the mean $\pm \mathrm{SD}$ of the behavior of 3 females analyzed for approximately $1 \mathrm{~min}$ each 
Table 3. Pseudocalanus elongatus. Fecal pellet feeding behavior in the presence (+alga) or absence (-alga) of alternative food (Thalassiosira weissflogii at concentrations of $3 \times 10^{6}$ cells $\mathrm{l}^{-1}$ ), during the half-hour analysis. Further details as in Table 2

\begin{tabular}{|c|c|c|c|c|c|c|c|c|c|c|}
\hline \multirow{3}{*}{$\begin{array}{l}\text { Pellet conc. } \\
\text { (pellets } \mathrm{ml}^{-1} \text { ) } \\
\text {-alga/+alga }\end{array}$} & \multicolumn{4}{|c|}{ Rejection } & \multicolumn{2}{|c|}{ Avoidance } & \multicolumn{2}{|c|}{ Ingestion } & \multicolumn{2}{|c|}{ Encounter } \\
\hline & & rust & Filtı & tion & & & & & & \\
\hline & -alga & +alga & -alga & +alga & -alga & +alga & -alga & +alga & -alga & +alga \\
\hline $0 / 0.1$ & 0 & 0 & 0 & 3 & 1 & 1 & 0 & 1 & 1 & 5 \\
\hline $1.25 / 1.25$ & 0 & 0 & 0 & 1 & 1 & 3 & 0 & 0 & 1 & 4 \\
\hline 3.5/3.1 & 9 & 5 & 8 & 11 & 2 & 0 & 6 & 0 & 25 & 16 \\
\hline $8.5 / 8.5$ & 5 & 2 & 3 & 8 & 0 & 2 & 1 & 1 & 9 & 13 \\
\hline $10.75 / 11$ & 11 & 5 & 16 & 49 & 1 & 2 & 1 & 7 & 29 & 63 \\
\hline $23.25 /-$ & 10 & - & 62 & - & 0 & - & 3 & - & 75 & - \\
\hline
\end{tabular}

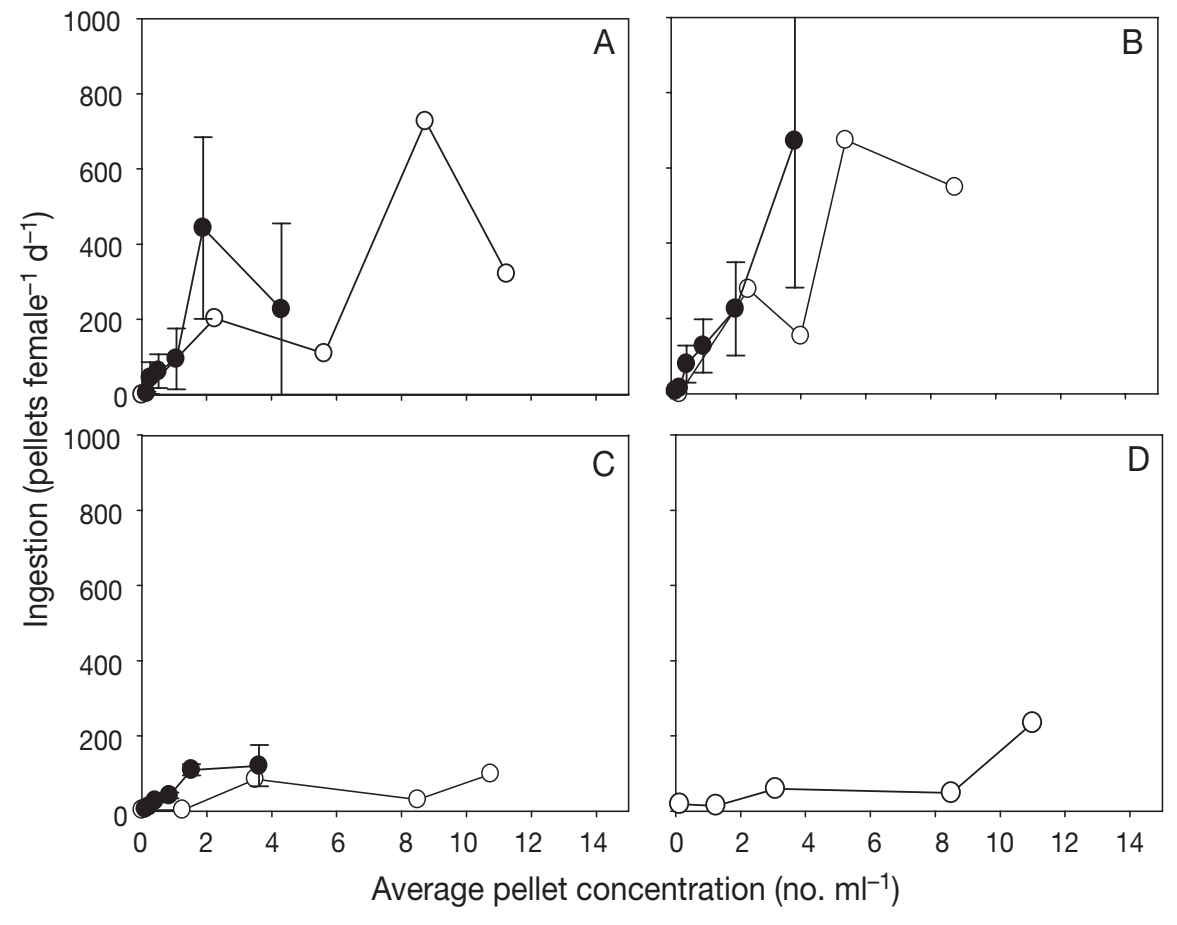

Fig. 7. (A,B) Calanus helgolandicus and (C,D) Pseudocalanus elongatus. Comparison between the ingestion rates of fecal pellets obtained from grazing experiments $(\bullet)$ and visual observations (O). Ingestion rates by $C$. helgolandicus and $P$. elongatus $(\mathrm{B}, \mathrm{D})$ with or $(\mathrm{A}, \mathrm{C})$ without an alternative food source (Thalassiosira weissflogii) are shown; ingestion rates from the visual observations were calculated from the percentage of observed ingestions and the total encounters of fecal pellets. Each point was calculated from the analysis of $30 \mathrm{~min}$ of video recording with a female in focus, assuming the behavior to be constant (halfhour analysis). Ingestion rates from the grazing experiments were estimated according to Frost (1972). Error bars indicate \pm SD

constant ingestion rate during $24 \mathrm{~h}$. Daily ingestion was calculated from the percentage of ingestions of the total encounters. The ingestion rates of Calanus helgolandicus and Pseudocalanus elongatus estimated from both video observations and from the grazing experiments (Figs. 1 \& 2) were compared by plotting them together (Fig. 7). No significant difference was found between the ingestion rates estimated from the video recordings and the grazing experiments for either C. helgolandicus or P. elongatus ( $\mathrm{p}>$ 0.5, ANCOVA). The ingestion rates obtained from the video observations showed that pellet ingestion rates of both $C$. helgolandicus and $P$. elongatus increased by a factor of 1.4 and 2.8, respectively, in the presence of an alternative food source. Further, the ingestion of $P$. elongatus was 3.4 times lower than the ingestion rate of $C$. helgolandicus in the presence of alternative food and 7 times lower when pellets were offered as the sole food (Fig. 7).

Thus, visual observation revealed that the increased clearance of fecal pellets in the presence of alternative food was caused by an increased suspension feeding activity by the calanoid copepods. The presence of alternative food induced uninten-

encountered more frequently when an alternative food source was present. Less than $20 \%$ of the encountered fecal pellets were ingested, independent of pellet concentrations (calculated from Tables $2 \& 3$ ).

Ingestion rates were estimated from the observed ingestions during the video recordings, assuming a tional ingestion of small pellet fragments along with the algae. Further, intact fecal pellets were avoided by both calanoid species. No feeding response was observed for Oithona similis during $7 \mathrm{~h}$ of filming, indicating that fecal pellets were generally not viewed as attractive food particles by any of the copepods. 


\section{DISCUSSION}

\section{Fecal pellet degradation by calanoid copepods}

The similarity of the ingestion rates obtained by visual observations and incubation experiments demonstrates that these 2 methods are consistent for the measurement of grazing rates.

Visual observations revealed that the presence of an alternative food source increased the ingestion rates of fecal pellets for both Calanus helgolandicus and Pseudocalanus elongatus. The same tendency was observed in the grazing experiments, but not at significant levels. The increased ingestion was due to increased suspension feeding activity initiated by the presence of the alternative food source. Increased feeding activity resulted in higher encounter rates of fecal pellets, and thus more modulation of the pellets. Other calanoid copepods (Acartia tonsa, Centropages hamatus, Eucalanus pileatus, and Temora longicornis) show similar increases in their functional response to fecal pellets in the presence of alternative algal food (Paffenhöfer \& Van Sant 1985, Lampitt et al. 1990, Poulsen \& Kiørboe 2005). Therefore, the degradation of fecal pellets by these suspension feeding calanoid copepod species is dependent on the feeding activity induced by other food particles.

Calanus helgolandicus and Pseudocalanus elongatus were observed to reject large fecal pellets at high rates, seemingly due to handling difficulty of the large particle sizes. Poulsen \& Kiørboe (2005) found that the clearance of pellets by calanoid copepods decreased with the relative increase in pellet size. Our pellet clearances obtained for the calanoid copepods fit well with the data from Poulsen \& Kiørboe (2005) (Fig. 8). We therefore support the view that pellet size is a controlling factor for the ability of a copepod to recognize the pellet as an unsuitable food particle. Further, pellet ingestion occurred only when the fragments were so small that they were ingested unintentionally along with the alternative food particles.

The high rejection rate was independent of pellet concentration or the presence or absence of an alternative food source. The total number of rejections increased when an alternative food source was present, due to increased pellet encounter rates. Often rejections led to membrane rupture, opening, and/or fragmentation of the pellet. The most common degradation process by Calanus helgolandicus and Pseudocalanus elongatus was therefore coprorhexy. Other investigators have also observed that calanoid copepods damage fecal pellets during rejection (Paffenhöfer \& Van Sant 1985, Noji et al. 1991, Poulsen \& Kiørboe 2005), supporting the view that the direct response to intact, large pellets from several calanoid copepods is rejection and coprorhexy.

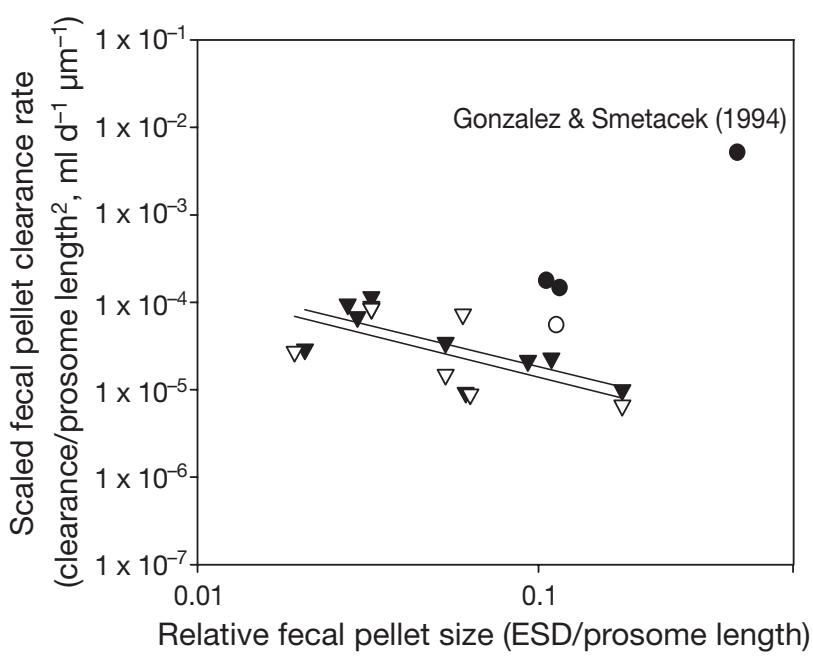

Fig. 8. Copepod fecal pellet clearance rate (normalized by copepod prosome length squared) as a function of relative pellet size (ESD/copepod prosome length) for calanoid copepods $(\nabla, \boldsymbol{\nabla})$ and Oithona similis $(\mathrm{O}, \bullet)$, in the absence (open symbols) or presence (closed symbols) of alternative food. Clearance rates and pellet sizes for the calanoid copepods were obtained from Table 5 in Poulsen \& Kiørboe (2005) and from the present study. Clearance rates and pellet sizes for $O$. similis were obtained from González \& Smetacek (1994) and the present study. The data point obtained from González \& Smetacek (1994) for $O$. similis is labeled with the reference. The regression for pellets as the sole food for the calanoid copepods is: $\log (y)=-0.97 \log (x)-5.83, \mathrm{R}^{2}=0.39$. The regression for pellets offered together with an alternative food source for the calanoid copepods is: $\log (y)=-0.95 \log (x)-5.69$,

$$
\mathrm{R}^{2}=0.53
$$

Coprochaly may also be an important degradation mechanism for Calanus helgolandicus. This was evident as females of this species were observed to remove and possibly ingest parts of the peritrophic membrane. This behavior was also observed for C. helgolandicus and Acartia clausi by Noji et al. (1991), who named the behavior coprochaly. It is therefore likely that $C$. helgolandicus feeds on bacteria and other organisms, which rapidly colonize the peritrophic membrane of fecal pellets after egestion (Hargrave 1975, Tezuka 1990), increasing the nutritional value of the pellet (Turner \& Ferrante 1979, Simon et al. 2002). The occurrence of coprochaly can be mistaken for coprorhexy without the inclusion of direct observations, since both coprochaly and coprorhexy impose physical stress on the pellet, causing pellet loosening or fragmentation. In situ loosening or fragmentation of pellets increases the residence time and thereby the microbial degradation of fecal pellets within the water column because the reduced particle size and/or density decreases the sinking velocity of the pellets. Therefore, coprorhexy and coprochaly are important degradation processes, which seem to be more com- 
mon feeding behaviors for calanoid copepods than coprophagy.

In conclusion, the importance of calanoid suspension feeding copepods for pellet degradation mainly seems to be indirect via the modulation of fecal pellets. The rate of the modulation is controlled by the presence of the alternative food, which induces suspension feeding. For copepods to have a significant effect on pellet degradation, situations with very high abundances of copepods in combination with small pellets would be needed (M. H. Iverson \& Poulsen unpubl. data). Further, plankton organisms $<200 \mu \mathrm{m}$ (Poulsen \& Kiørboe 2006) and more specifically large protozooplankton $(>20 \mu \mathrm{m})$ play a dominant role in the degradation of fecal pellets (M. H. Iverson \& Poulsen unpubl. data).

\section{Fecal pellet degradation by Oithona similis}

Visual observation of numerous situations in which Oithona similis was within detection distance of a fecal pellet did not result in the launch of an attack (calculation of critical detection distance was done according to Kiørboe \& Visser 1999). Thus, O. similis did not seem to view fecal pellets as suitable food items. However, the grazing experiments indicated ingestion of fecal pellets by $O$. similis. Further, ingestion and clearance rates increased when an alternative food source was present, although only at significant levels when pellets were offered together with Rhodomonas salina. These findings are contrary to our expectations. We expected the grazing rates to be independent of the presence or absence of an alternative food source, since $O$. similis uses hydromechanical signals to perceive its prey particles. These signals do not change in the presence or absence of small food particles, and the feeding behavior should stay constant in both situations. Therefore, since a suitable alternative food source increased pellet removal, we suggest that the presence of alternative food triggers $O$. similis into a feeding mode in which it fragments or ingests fecal pellets at increased rates.

The obtained average fecal pellet removal rates for Oithona similis are low compared to removal rates reported by González \& Smetacek (1994). At similar pellet concentrations, we found that the removal of pellets by $O$. similis was lower than the rates found by González \& Smetacek (1994) by a factor of 5000 when offering calanoid pellets with an algal monoculture, and lower by a factor of 500 when offered with a natural plankton assemblage. In contrast, Reigstad et al. (2005) observed a complete lack of fecal pellet removal by $O$. similis when offering the same pellet type as used by González \& Smetacek (1994). In the study by
González \& Smetacek (1994), O. similis presumably grazed large pellets lying on the bottom of standing experimental bottles. This contradicts the results of several studies of grazing behavior, which show that $O$. similis is an ambush feeder that perceives its prey by detecting the hydromechanical disturbance generated when the prey is sinking or swimming (Paffenhöfer 1993, Kiørboe \& Visser 1999, Svensen \& Kiørboe 2000). Accordingly, the pellets must be sinking in order to be detected. To detect pellets on the bottom of a bottle, chemosensory perception is needed. Chemosensory perception of small prey such as fecal pellets requires a feeding current (Andrews 1983), and since $O$. similis lacks the ability to suspension feed (Svensen \& Kiørboe 2000), the detection of pellets lying on the bottom is unlikely. We therefore question the fact that the high removal rate of pellets lying on the bottom of the bottles was due to ingestion by $O$. similis.

In our study and in the study by Reigstad et al. (2005), constant generation of hydromechanical signals from the pellets was generated by rotation of the incubation bottles on a plankton wheel. This approaches the situation in situ where Oithona similis only encounters sinking fecal pellets. Thus, evidence from our study and 3 field studies shows that $O$. similis does not have a significant effect on fecal pellet degradation (Sampei et al. 2004, Reigstad et al. 2005, Poulsen \& Kiørboe 2006, M. H. Iverson \& Poulsen unpubl. data).

It may be argued that the low degradation rates of pellets obtained by Reigstad et al. (2005) and in our experiments were caused by the inability of Oithona similis to perceive the pellets hydromechanically due to water mixing in the rotating incubation bottles ( $1 \mathrm{rpm})$. However, after a short spin up and down, there will be no turbulence in the bottles. Further, in our study, the rotation speed was slow enough not to disturb $O$. similis and fast enough to prevent the pellets from encountering the sides of the bottle when sinking. Thus, hydromechanical perception was not disturbed, and water mixing cannot explain the lower degradation rates. Another study of visual observation of ambush feeding Acartia tonsa females in a rotating aquarium (similar setup as in this study) supports this, as $A$. tonsa was able to detect, attack, and ingest fecal pellets using hydromechanical signals (Poulsen \& Kiørboe 2005). We therefore agree with Reigstad et al. (2005), who hypothesized that $O$. similis is an indicator species for high degradation regimes but does not necessarily degrade the pellets itself. This is possible since Oithona spp. are often abundant in plankton communities that mainly consist of small copepods. Thus, the produced fecal pellets are small, with low sinking rates that increase the time available for degradation. 
Poulsen \& Kiørboe (2006) found high degradation of pellets $(61$ to $97 \%$ ) in the upper $50 \mathrm{~m}$ of the water column during a field study of vertical flux and pellet degradation. However, they observed low pellet degradation when incubating only large zooplankton organisms $(>200 \mu \mathrm{m})$, indicating that copepods and other mesozooplankton did not affect pellet degradation significantly. We previously investigated the degradation of different size fractions of the plankton community in The Sound (Denmark) in more detail and likewise found that copepods and other mesozooplankton did not affect pellet degradation significantly (M. H. Iverson \& Poulsen unpubl. data). Further, we (unpubl. data) found protozooplankton and bacteria to be the main degraders of fecal pellets in the sea. We therefore suggest that copepods play a minor role in direct pellet degradation in situ and mainly influence the degradation through fragmentation of the pellets. However, via the grazing pressure imposed by the copepods on the effective pellet degraders such as large protozooplankton $(>20 \mu \mathrm{m})$ and possibly nauplii, they are indirectly very important for the downward export of fecal pellets (M. H. Iverson \& Poulsen unpubl. data).

Acknowledgements. We thank Prof. T. Kiørboe, Danish Institute for Fisheries Research, Department of Marine Ecology and Aquaculture for comments and support during the experimental phase. L.K.P. was supported by the Scaling from Individual to Population (SLIP) research school under the Danish Network for Fisheries and Aquaculture Research financed by the Danish Ministry for Food, Agriculture, and Fisheries and the Danish Agricultural and Veterinary Research Council. M.H.I. was supported by the Danish Institute for Fisheries Research, Department of Marine Ecology and Aquaculture.

\section{LITERATURE CITED}

Andrews JC (1983) Deformation of the active space in the low Reynolds-number feeding current of calanoid copepods. Can J Fish Aquat Sci 40:1293-1302

Besiktepe S, Dam HG (2002) Coupling of ingestion and defecation as a function of diet in the calanoid copepod Acartia tonsa. Mar Ecol Prog Ser 229:151-164

Cho BC, Azam F (1988) Major role of bacteria in biogeochemical fluxes in the ocean's interior. Nature 332:441-443

Frost BW (1972) Effects of size and concentration of food particles on the feeding behavior of the marine planktonic copepod Calanus pacificus. Limnol Oceanogr 6:805-815

González HE, Smetacek V (1994) The possible role of the cyclopoid copepod Oithona in retarding vertical flux of zooplankton fecal material. Mar Ecol Prog Ser 113:233-246

Green EP, Harris RP, Duncan A (1992) The production and ingestion of fecal pellets by nauplii of marine calanoid copepods. J Plankton Res 14:1631-1643

Guillard RRL (1975) Culture of phytoplankton for feeding marine invertebrates. In: Smith WL, Chanley MH (eds) Culture of marine invertebrate animals. Plenum Press, London, p 29-60
Hargrave BT (1975) The central role of invertebrate faeces in sediment decomposition. In: Anderson JM, Macfadyen A (eds) The role of terrestrial and aquatic organisms in decomposition processes. Blackwell Scientific Publications, London, p 301-321

Kiørboe T, Visser AW (1999) Predator and prey perception in copepods due to hydromechanical signals. Mar Ecol Prog Ser 179:81-95

Kiørboe T, Möhlenberg F, Riisgaard HU (1985) Bioenergetics of the planktonic copepod Acartia tonsa: relation between feeding, egg production and respiration, and composition of specific dynamic action. Mar Ecol Prog Ser 26:85-97

Lampitt RS, Noji T, von Bodungen B (1990) What happens to zooplankton fecal pellets -implications for material flux. Mar Biol 104:15-23

Noji TT, Estep KW, MacIntyre F, Norrbin F (1991) Image analysis of fecal material grazed upon by three species of copepods: evidence for coprorhexy, coprophagy and coprochaly. J Mar Biol Assoc UK 71:465-480

Paffenhöfer GA (1993) On the ecology of marine cyclopoid copepods (Crustacea, Copepoda). J Plankton Res 15:37-55

Paffenhöfer GA, Knowles SC (1979) Ecological implications of fecal pellet size, production and consumption by copepods. J Mar Res 37:35-49

Paffenhöfer GA, Strickland JDH (1970) A note on the feeding of Calanus helgolandicus on detritus. Mar Biol 5:97-99

Paffenhöfer GA, Van Sant KB (1985) The feeding response of a marine planktonic copepod to quantity and quality of particles. Mar Ecol Prog Ser 27:55-65

Ploug $\mathrm{H}$, Iversen $\mathrm{MH}$, Koski M, Buitenhuis ET (in press) Production, oxygen respiration rates, and sinking velocities of copepod fecal pellets: direct measurements of ballasting by opal and calcite. Limnol Oceanogr

Poulsen LK, Kiørboe T (2005) Coprophagy and coprorhexy in the copepods Acartia tonsa and Temora longicornis: clearance rates and feeding behavior. Mar Ecol Prog Ser 299: $217-227$

Poulsen LK, Kiørboe T (2006) Vertical flux and degradation rates of copepod fecal pellets in a zooplankton community by small copepods. Mar Ecol Prog Ser 323:195-204

Reigstad M, Wexel-Riser C, Svensen C (2005) Fate of copepod faecal pellets and the role of Oithona spp. Mar Ecol Prog Ser 225:265-270

Sampei M, Sasaki H, Hattoi H, Fukuchi M, Hargrave BT (2004) Fate of sinking particles, especially fecal pellets, within the epipelagic zone in the North Water (NOW) polynya of northern Baffin Bay. Mar Ecol Prog Ser 278: $17-25$

Simon M, Grossart HP, Schweitzer B, Ploug H (2002) Microbial ecology of organic aggregates in aquatic ecosystems. Aquat Microb Ecol 28:175-211

Støttrup JG, Richardson K, Kirkegaard E, Pihl NJ (1986) The cultivation of Acartia tonsa Dana for use as a live food source for marine fish larvae. Aquaculture 52:87-96

Svensen C, Kiørboe T (2000) Remote prey detection in Oithona similis: hydromechanical versus chemical cues. J Plankton Res 22:1155-1166

Tezuka Y (1990) Bacterial regeneration of ammonium and phosphate as affected by the carbon-nitrogen-phosphorus ratio of organic substrates. Microb Ecol 19:227-238

Turner JT, Ferrante JG (1979) Zooplankton fecal pellets in aquatic ecosystems. BioScience 29:670-677

Viitasalo M, Rosenberg M, Heiskanen AS, Koski M (1999) Sedimentation of copepod fecal material in the coastal northern Baltic Sea: Where did all the pellets go? Limnol Oceanogr 44(6):1388-1399

Submitted: August 29, 2006; Accepted: June 6, 2007

Proofs received from author(s): November 1, 2007 